\title{
Risk Management of Obese Women Undergoing Major Gynaecological Surgery
}

\author{
Avni Batish1, Rotimi A. K. Jaiyesimi² \\ ${ }^{1}$ Princes Royal University Hospital, Kings College Hospital NHS Foundation Trust, London, UK \\ ${ }^{2}$ Basildon and Thurrock University Hospitals, Basildon, UK \\ Email: a.batish@nhs.net
}

Received 25 April 2014; revised 23 May 2014; accepted 18 June 2014

Copyright (C) 2014 by authors and Scientific Research Publishing Inc.

This work is licensed under the Creative Commons Attribution International License (CC BY). http://creativecommons.org/licenses/by/4.0/

(c) (i)

\begin{abstract}
Obesity is a big problem which is growing. Thus clinicians and surgeons are likely to treat obese patients more frequently. Obesity can affect medical practice in a number of ways. In order to protect ourselves from potential litigation, we need to focus on risk management efforts on creating a safe environment for patients of all sizes. The aim of our study was to review the risk management strategies of obese women prior to surgery, perioperatively and following surgery. We then identified the strategies and have brought them forward in our article.
\end{abstract}

\section{Keywords}

Obesity, Risk Management, Anaesthetic Complications, Major Gynaecological Surgery

\section{Introduction}

Obesity is defined as an excess of adipose tissue [1]. In 1997, the WHO attempted to standardise the definition of obesity as a BMI above $30 \mathrm{~kg} / \mathrm{m}^{2}$ [2]. Thus overweight is defined as BMI between 25 and 29.9. Class 1obesity is a BMI between 30 and 34.9, class 2 between 35 and 39.9 and class 3 a BMI above 40 [3]. The general accepted definition of morbidly obese is a BMI greater than 40 [1]. Individuals with a BMI > 35 and comorbidity should be managed as for those with a BMI > 40.4 [4] (Table 1).

An estimated 30,000 deaths in the UK each year are attributable to obesity [6]. Mokdad et al. [7] found an almost doubling in incidence of obesity in women in the USA in a 10 year period from 1991-2001.The prevalence of obesity is increasing and about one third of the population of the industrialised countries is at least $20 \%$ overweight [8].

Obesity is a known risk factor for development of endometrial cancer and with the increased prevalence of obesity we are likely to encounter an increased number of obese women with endometrial cancer [9]. Also we 
Table 1. Classification of BMI [5].

\begin{tabular}{ccc}
\hline Obese & $\geq \mathbf{3 0 . 0 0}$ & $\geq \mathbf{3 0 . 0 0}$ \\
\hline Obese class I & $30.00-34.99$ & $30.00-32.49$ \\
& & $32.50-34.99$ \\
Obese class II & $35.00-39.99$ & $35.00-37.49$ \\
Obese class III & $\geq 40.00$ & $37.50-39.99$ \\
\hline
\end{tabular}

Source: Adapted from WHO, 1995, WHO, 2000 and WHO 2004.

should be aware of the main hazards of operating upon obese women-blood loss, infection and thromboembolism [10]. Reasons for complications in morbidly obese patients can be attributed to technical difficulties in operating on obese patients; operations taking more time, thus increasing the chances of contamination; more trauma; and even necrosis of the abdominal wall because of more forceful retraction during surgery. As we have identified that obese women undergoing surgery are at risk, we should allow interventions that aim to eliminate, or at least minimise, pre and post operative surgical complications and improve patient outcome ; hence the need for risk management.

Risk management involves practical steps to protect people from the risk that cause real harm and suffering. Though having a protocol or guideline for management of obese women is useful yet each case should be individualised. Risk management involves risk identification. We know that women with polycystic ovarian syndrome are at an increased risk of developing obesity and future risk of endometrial carcinoma [11] thus we should aim for disseminating information including long term risks and life style changes to women diagnosed with polycystic ovarian syndrome.

As usually the General Practitioner refers the patients who might need operating upon hence they should stress the importance of weight loss prior to referral. When seen in clinic each case should be individualised and alternate treatment options be sought. If surgery is indicated; again weight loss should be stressed upon. Almost all the patients would be aware of their obesity hence it is important to discuss the issue sensitively. Referral to dietician should be considered.

\section{Preoperative Measures}

\subsection{Anaesthetic Review}

Pre op assessment of obese women undergoing major gynaecological surgery should be in conjunction with the anaesthetist. We know that obesity has effect on perioperative lung volumes. Clinically obese patients appear to have worse respiratory function after surgery [12] [13]. In a prospective study of 161 women conducted in Switzerland demonstrated that all perioperative values decreased significantly with increasing BMI [14]. As expiratory lung volume is reduced in obese patients, obesity is associated with a decrease in functional residual capacity and vital capacity [15]-[17] and thus an enhanced response to GA compared with normal weight patients [18].

\subsection{Thromboprophylaxis and Antibiotic Prophylaxis}

Obese women undergoing surgery need to have pre op thromboprophylaxis as well as antibiotic prophylaxis. There should be an agreed protocol for antibiotic prophylaxis according to surgery. Also as obese women are more prone for blood loss during surgery measures should be advocated for good pro operative haemoglobin in women undergoing surgery particularly for fibroids associated with menorrhagia.

\subsection{Consent Form}

Consent forms an integral part of risk management as well is an important part of clinical practice. The aim is to insure that all patients are given consistent and adequate information for consent. In a study done in USA which 
was a retrospective chart review they compared complications and rate of conversion to laparotomy between normal weight, preobese and obese women who underwent laparoscopic management of benign adnexal mass [19]. They found out that obese women were 13 likely to undergo conversion to laparotomy than normal weight women thus associating with a longer hospital stay. Therefore obese and pre obese women should be counselled extensively on morbidity associated with laparoscopy.

\section{Operative Measures}

Theatre Logistics/Equipment: Another area where we can reduce the risk is the theatres. We are all aware of the limitations of operating tables with the weight limits and other health and safety issues regarding transferring of obese women onto operating table. Do we always inform the relevant theatre staff the BMI of the lady we are operating upon? If consideration is given to the above thought it would reduce the last minute rush to change the operating table or finding more assistants to transfer the lady on to the table thus adding on to the already short theatre time available leading onto delay in the theatre list. Also how often in the ward we have seen that they are unable to provide correct size of TED stocking as the staff were not fully prepared for a very obese pre op lady. As gynaecological surgery is usually an elective situation, therefore there should be time to have the patient measured and a customised pair made.

Prior to starting the operation the surgeon should make sure of the instruments available as standard surgical equipment does not facilitate access to the pelvis in an obese woman ${ }^{8}$. The surgeon should also make sure that he has good assistant with him while operating.

Choice of surgery (vaginal/abdominal hysterectomy) for benign gynaecological conditions is another issue which needs to be looked into. A study group from USA comprising of 369 obese women concluded that for obese women, vaginal hysterectomy is superior due to its lower incidence of post of fever, ileus, UTI, shorter operative time and hospital stay [20].

A prospective comparative clinical study of 271 laparoscopic hysterectomies performed for disease of pelvic organ in a group of 54 obese women and in a group of 217 non obese women done in Czech Republic demonstrated that the rate of major operative complications (5.55\% vs. $3.22 \%$ ) was higher in the obese group. The duration of operation also was longer in obese women. However the significance of difference was borderline $(\mathrm{P}=$ $0.06)$ [21].

Surgery in patients who are obese and morbidly obese represents a challenge for every surgeon. Wound complication rates are uniformly higher in patients who are obese, regardless of the type of incision. Obtaining adequate surgical exposure requires patience, understanding of changes in anatomical landmarks, and proper surgical equipment.

The abdominal wall landmarks are distorted in patients who are obese, particularly in the presence of a large panniculus. Care is needed not to buttonhole the skin under the panniculus. Use of a ring retractor, such as the Bookwalter, optimizes surgical exposure.

The abdominal panniculus itself can cause problems with the wound, as the overhanging skin and subcutaneous tissue create a subpannicular area that is prone to increased moisture, chronic skin maceration, and elevated bacteria counts causing higher incidence of wound infection, necrosis, and dehiscence. Removal of excess skin and subcutaneous adipose tissue by abdominal panniculectomy can improve the appearance and hygiene of the abdomen, decrease wound infection rates, and improve exposure to the abdomen and pelvis, including the retroperitoneum, which makes difficult pelvic operations safe and optimal, with very low morbidity rates. Twenty morbidly obese women had excision of large abdominal panniculiin conjunction with pelvic surgery at New Hanover Regional Medical Center between November 1994 and September1998. The conclusion was that abdominal panniculectomy is safe and useful in morbidly obese women.

\section{Post Operative Measures}

Post operative complications are higher in obese women. Obese women are more prone to bleeding and thus more frequent return to theatre. Therefore in the consent form we must make sure that things have been covered including "return to theatre". The operation notes must be clear and legible and must be completed on the day of surgery in view of the above circumstance. Any difficulty encountered must be clearly mentioned. Thromboprophylaxis is essential. The use of regional anaesthesia is to be encouraged: as well as the anaesthetic benefits, this helps with postoperative analgesia and reduces the risk of thromboembolism by half [22]. It is well recog- 
nised that the risk of perioperative deep vein thrombosis and pulmonary embolism is higher among obese people than among those ofnormal weight [22]. Prompt mobilization and avoidance of dehydration is important. It is also important to discuss wound hygiene with the patient.

Following discharge of the lady from the hospital it is essential that the findings and outcome of the women is communicated to the General Practitioner.

\section{Conclusion}

In summary, risk management strategies for obese women can start in the community with the general practitioner giving counselling or referral for counselling, e.g. smoking cessation, preoperative dietary advice etc. In clinic, the surgeon needs to treat each patient individually and develop a treatment plan accordingly. A careful case selection is thus needed. Each patient should be individually risk assessed and the care and treatment for that patient should be consultant led. The preoperative assessment of obese women should be thorough with details for thromboprophylaxis. Intra operative measures, as mentioned above in our article, help to reduce the complications and hence decrease the risk for potential litigation. Planning for postoperative care (location, analgesia, physiotherapy, thromboprophylaxisetc) should be in place and the patients' general practitioner should be informed of the outcome. All these risk strategies would reduce the risk for the potential litigation.

\section{References}

[1] Yu, C.K.H., Cutner, A., Mould, T. and Olaitan, A. (2005) Total Laparoscopic Hysterectomy as a Primary Surgical Treatment for Endometrial Cancer in Morbidly Obese Women. BJOG, 11, 115-117.

[2] Basdevant, A. (2000) Obesity: Epidemiology and Public Health. Annales d Endocrinologie (Paris), 61, 6-11.

[3] (1998) Executive Summary of the Clinical Guidelines on the Identification, Evaluation and Treatment of Overweight and Obesity in Adults. Archives of Internal Medicine, 158, 1855-1867. http://dx.doi.org/10.1001/archinte.158.17.1855

[4] Association of Anaesthetists of Great Britain and Ireland (2007) Perioperative Management of the Morbidly Obese Patient. AAGBI, London.

[5] Adapted from WHO, 1995, WHO, 2000 and WHO 2004.

[6] Haslam, D.W. and James, W.P.T. (2005) Obesity. Lancet, 366, 1197-1209. http://dx.doi.org/10.1016/S0140-6736(05)67483-1

[7] Mokdad, A.H., Serdula, M.K., Dietz, W.H., Bowman, B., Marks, J.S. and Koplan, J.P. (2000) The Spread of the Obesity Epidemic in the United States, 1991-1998. JAMA, 284, 1650-1651. http://dx.doi.org/10.1001/jama.284.13.1650

[8] Kuczmarski, R.J., Flegal, K.M. and Campbell, C.L. (1994) Increasing Prevalence of Overweight among US Adults. The National Health and Nutrition Surveys 1960-1991. JAMA, 272, 205-211. http://dx.doi.org/10.1001/jama.1994.03520030047027

[9] Everett, E., Tamimi, H., Greer, B., et al. (2003) The Effect of Body Mass Index on Clinical/Pathological Features, Surgical Morbidity, and Outcome in Women with Endometrial Cancer. Gynecologic Oncology, 90, 150-157. http://dx.doi.org/10.1016/S0090-8258(03)00232-4

[10] Alexander, C. and Liston, W. (2006) Operating on the Obese Woman-A Review. BJOG, 113, 1167-1172. http://dx.doi.org/10.1111/j.1471-0528.2006.01073.x

[11] Dewhurst's Textbook for Obstetrics and Gynaecology

[12] Hansen, G., Drablos, P.A. and Steinert, R. (1977) Pulmonary Complications. Ventilation and Blood Gases after Upper Abdominal Surgery. Acta Anaesthesiologica Scandinavica, 21, 211-215.

http://dx.doi.org/10.1111/j.1399-6576.1977.tb01211.x

[13] Eriksen, J., Andersen, J. and Rasmussen, J.P. (1977) Postoperative Pulmonary Function in Obese Patients after Upper Abdominal Surgery. Acta Anaesthesiologica Scandinavica, 21, 336-341. http://dx.doi.org/10.1111/j.1399-6576.1977.tb01228.x

[14] von Ungern-Strenberg, B.S., Regli, A., Schneider, M.C., Kunz, F. and Reber, A. (2004) Effect of Obesity and Site of Surgery on Perioperative Lung Volumes. British Journal of Anaesthesia, 92, 202-207. http://dx.doi.org/10.1093/bja/aeh046

[15] Luce, J.M. (1980) Respiratory Complications of Obesity. Chest, 78, 626-631. http://dx.doi.org/10.1378/chest.78.4.626

[16] Ray, C., Sue, D., Bray, G., et al. (1983) Effects of Obesity on Respiratory Function. The American Review of Respiratory Disease, 128, 501-506.

[17] Barrera, F., Reidenberg, M. and Winters, W. (1967) Pulmonary Function in the Obese Patient. The American Journal 
of Medicine, 254, 785-796. http://dx.doi.org/10.1097/00000441-196712000-00003

[18] Waltemath, C.L. and Bergman, N.A. (1974) Respiratory Compliance in Obese Patients. Anesthesiology, 41, 84-85. http://dx.doi.org/10.1097/00000542-197407000-00022

[19] Thomas, D., Ikeda, M., Deepika, K., Medlina, C. and Takacs, P. (2006) Laparoscopic Management of Benign Adnexal Mass in Obese Women. Journal of Minimally Invasive Gynecology, 13, 311-314.

[20] Isik-Akbay, E.F., Harmanli, O.H., Panganamamula, U.R., Akbay, M., Gaughan, J. and Chatwani, A.J. (2004) Hysterectomy in Obese Women: A Comparison of Abdominal and Vaginal Routes. Obstetrics and Gynecology, 104, 710714.

[21] Houlb, Z., Jabor, A., Kliment, L., Fischlova, D. and Wagnerova, M. (2001) Laparoscopic Hysterectomy in Obese Women: A Clinical Prospective Study. European Journal of Obstetrics Gynecology and Reproductive Biology, 98, 7782.

[22] National Institute for Health and Clinical Excellence (2009) Venous Thromboembolism: Reducing the Risk of Thromboembolism (Deep Vein Thrombosis and Pulmonary Embolism) in Patients Admitted to Hospital. Clinical Guideline CG92. NICE, London. 
Scientific Research Publishing (SCIRP) is one of the largest Open Access journal publishers. It is currently publishing more than 200 open access, online, peer-reviewed journals covering a wide range of academic disciplines. SCIRP serves the worldwide academic communities and contributes to the progress and application of science with its publication.

Other selected journals from SCIRP are listed as below. Submit your manuscript to us via either submit@scirp.org or Online Submission Portal.
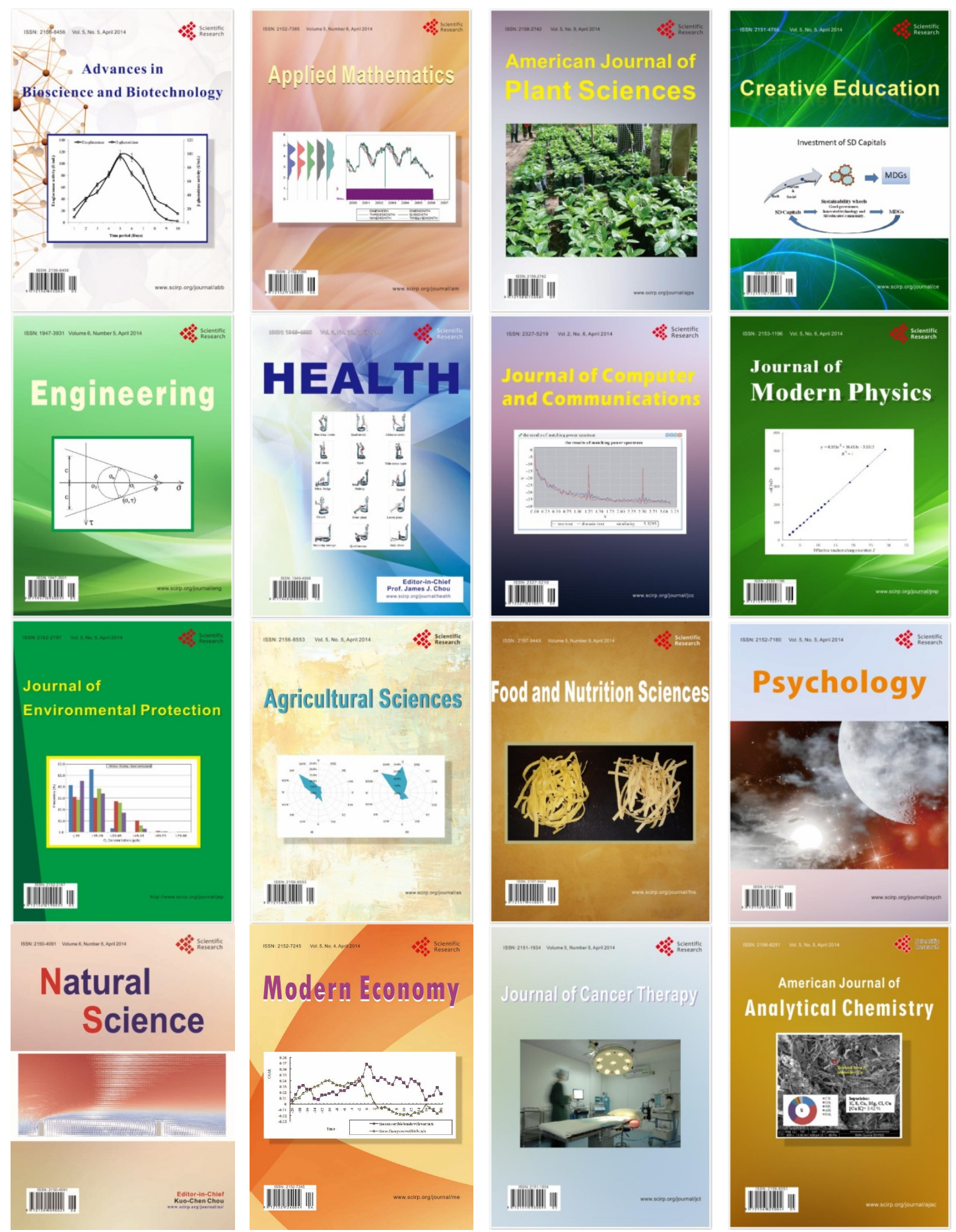